\title{
Relato sobre a pesca do robalo no Canal de Bertioga durante a Pandemia COVID-19
}

\author{
Report on snook fishing in the Bertioga Canal during the COVID-19 Pandemic \\ Informe sobre la pesca de lubina en el Canal de Bertioga durante la pandemia de COVID-19
}

Recebido: 05/05/2021 | Revisado: 10/05/2021 | Aceito: 12/05/2021 | Publicado: 29/05/2021

\author{
Adele Raquel Laurelli \\ ORCID: https://orcid.org/0000-0002-2509-3173 \\ Universidade Santa Cecília, Brasil \\ E-mail: adelerachellaurelli@gmail.com \\ Milena Ramires \\ ORCID: https://orcid.org/0000-0002-7686-0838 \\ Universidade Santa Cecília, Brasil \\ E-mail: milena@unisanta.br \\ Walter Barrella \\ ORCID: https://orcid.org/0000-0001-9038-7840 \\ Universidade Santa Cecília, Brasil \\ Universidade Paulista, Brasil \\ E-mail: walterbarrella@gmail.com
}

\begin{abstract}
Resumo
O Canal de Bertioga é delimitado pelo continente e pela ilha de Santo Amaro, constituindo a unidade natural que conecta os municípios de Santos, Guarujá e Bertioga com o oceano. É considerado como uma das regiões mais visitadas por pescadores amadores no estado de São Paulo. A presente pesquisa buscou analisar alterações na prática da pesca amadora de robalos, no canal de Bertioga, decorrentes dos impactos da pandemia do COVID-19. Foi visitado, entre fevereiro e abril de 2021, um ponto de embarque localizado no trecho sul deste canal, com o objetivo de inventariar as condições e serviços oferecidos aos pescadores esportivos da região, durante o período de restrição provocado pela pandemia COVID-19. Neste local, os principais serviços são aluguel de barcos e motores de popa, além de venda de camarões como iscas vivas. No período de fechamento do comércio varejista, barcos foram alugados com maior frequência para pescadores esportivos, em dias que, frequentemente, não havia grande exercício dessa atividade, como em dias úteis da semana. Relatos sobre a intensa movimentação de barcos, que trafegam acima da velocidade permitida (5 nós) desestabilizando as margens e a vegetação do manguezal foram apontados como um impacto do período de restrição. A pesca irregular, com rede de "malhão" também tem provocado danos ambientais, com a redução da biodiversidade aquática no canal. Enfatizamos a atuação das políticas públicas no setor, garantindo saúde, segurança alimentar e geração de renda, amenizando a crise e recuperando economias locais.
\end{abstract}

Palavras-chave: Centropomus; Manguezal; Lockdown.

\begin{abstract}
The Bertioga Canal is bounded by the continent and the island of Santo Amaro, constituting the natural unit that connects the municipalities of Santos, Guarujá and Bertioga with the ocean. It is considered as one of the most visited regions by recreational fishermen in the state of São Paulo. The present research analyzed changes in the practice of recreational fishing for snooks, in the Bertioga channel, resulting from the impacts of the pandemic of COVID-19. Between February and April 2021, a boarding point located in the southern section of this channel was visited, to inventory the conditions and services offered to recreational fishermen in the region, during the period of restriction caused by the pandemic of COVID-19. In this location, the main services are boat rentals and outboard engines, in addition to selling shrimp as live bait. In the period of the closing of the retail trade, boats were rented more frequently to recreational fishermen, on days that, frequently, there was not great exercise of this activity, as on weekdays of the week. Reports of the intense movement of boats, which travel above the permitted speed ( 5 knots) destabilizing the margins and vegetation of the mangrove were pointed out as an impact of the restriction period. Irregular fishing, using "malhão" nets, has also caused environmental damage, with the reduction of the aquatic biodiversity in the channel. We emphasize the performance of public policies in the sector, guaranteeing health, food security and income generation, mitigating the crisis and recovering local economies.
\end{abstract}

Keywords: Centropomus; Mangrove; Lockdown.

\section{Resumen}

El Canal de Bertioga está delimitado por el continente y por la Isla de Santo Amaro, constituyendo una unidad natural que conecta los municipios de Santos, Guarujá y Bertioga como un océano. Es considerada una de las regiones más visitadas por los pescadores deportivos en el estado de São Paulo. Actualmente, la investigación busca analizar cambios en la práctica de la pesca lubina, no en el canal Bertioga, debido a dos impactos de la pandemia COVID-19. Entre 
febrero y abril de 2021 se visitó un punto de embarque ubicado en las cercanías de este canal, con el fin de relevar las condiciones y servicios ofrecidos a los pescadores deportivos de la región, durante el período de restricción provocado por la pandemia COVID-19. En esta ubicación, los principales servicios son el alquiler de embarcaciones y motores fuera de borda, además de la venta de camarones en cebos vivos. Sin una fecha para el comercio de ciervos, los barcos se alquilan con mayor frecuencia para los pescadores deportivos, en los días en que a menudo no hay gran actividad, como los días de semana. Las historias sobre el intenso movimiento de los barcos, que desacelera la velocidad permitida ( $5 \mathrm{~ns}$ ), desestabilizando los márgenes de los manglares y la vegetación, fueron contrarrestadas como un impacto del período de restricción. La pesca irregular, la red de "malhão", también ha causado daños ambientales, con una reducción de la biodiversidad acuática fuera del canal. Destacamos la implementación de políticas públicas no relevantes, garantizando salud, seguridad alimentaria y generación de ingresos, mitigando crisis y recuperando economías locales. Palabras clave: Centropomus; Mangle; Aislamiento.

\section{Introdução}

Os robalos (Família Centropomidae) são peixes muito procurados por pescadores esportivos e pescadores profissionais, devido à emoção da captura e ao alto valor de sua carne (da Silveira Menezes, 2012; Barrella et al., 2016; Motta et al., 2016; Molitzas et al. 2019). Esses peixes têm capacidade de sobrevivência em águas com baixa salinidade, sendo propicio o seu desenvolvimento, tanto em água doce como em água salobra e com baixo índice de oxigenação (Ager et al., 1976; Peterson \& Gilmore, 1991; Pereira et al., 2015 e 2020). Estas condições estão presentes no Bioma Manguezal (CIMA, 1991) que predomina no Canal de Bertioga. A proximidade das regiões metropolitanas de São Paulo e da Baixada Santista, favorece a alta frequência de pescadores amadores nesta área pertencente ao Estado de São Paulo, Região Sudeste do Brasil (Fujimoto et al., 2009; Nascimento et al., 2010). Além disto, os robalos modificam seus hábitos ao longo de seus ciclos vitais. Peixes em fase adulta consomem outros peixes, são solitários e preferem regiões mais profundas do Canal. Já os peixes mais jovens, procuram crustáceos e formam cardumes com amplo deslocamento no ambiente de manguezal (Chávez, 1963; Carvajal, 1975; Peters et al., 1998)

O recurso pesqueiro brasileiro tem potencial para atrair pescadores do mundo todo, principalmente, nas águas continentais, estuarinas e costeiras, que abrigam muitas espécies de peixes considerados esportivos, o que proporciona inúmeras oportunidades para a atividade (Brasil, 2010). É evidente que as duas modalidades, a esportiva e a profissional, requerem organização e planejamento, para prevenir impactos negativos sobre o estoque pesqueiro e o ambiente (Ramires \& Molina, 2004). Atualmente a pesca esportiva tem recebido uma atenção maior, pois gera trabalho e renda para as famílias de pescadores de pequenas comunidades que aplicam seus conhecimentos sobre os recursos pesqueiros nesta nova prática. É uma das atividades de turismo e lazer mais praticadas em todo o mundo, envolvendo uma série de serviços como transporte, alimentação e hospedagem adquiridos pelos pescadores esportivos (Barcellini et al., 2013). Pode ser considerada uma atividade de grande capacidade adaptativa, pois, continua sendo praticada, até mesmo em situações adversas, como é o caso do período de pandemia

da Covid-19. Embora os impactos da pandemia do Covid-19 tenham revelado uma ameaça concreta e imediata à segurança alimentar e nutricional de populações vulneráveis, particularmente povos e comunidades tradicionais (Gurgel et al., 2020), os serviços prestados para a pesca esportiva se adaptaram para continuar sendo oferecidos aos pescadores. Desta forma, a presente pesquisa buscou analisar alterações na prática da pesca de robalos, no canal de Bertioga, decorrentes dos impactos da pandemia do COVID-19.

\section{Metodologia}

O Canal de Bertioga, localizado no litoral do estado de São Paulo, é delimitado pelo continente e pela ilha de Santo Amaro, constituindo a unidade natural que conecta os municípios de Santos, Guarujá e Bertioga (Figura 1), representando uma segunda conexão do complexo estuarino de Santos-São Vicente com o oceano (Barbanti et al., 2013). Está geograficamente caracterizado como pertencente a Zona Térmica Tropical, sendo o clima característico da região de estudo identificado como 
Tropical Chuvoso, com precipitação alta e bem distribuída ao longo do ano todo classificado segundo Köppen-Geiger (IBGE, 2004). A vegetação característica de manguezal, alimentado hidricamente por um braço do Oceano Atlântico (água salgada) e pelo Rio Itapanhaú (água doce). O terreno do canal é de nível baixo, muito próximo do nível do mar, cuja baixa densidade de drenagem provoca a formação de meandros de rios e áreas alagadas, além das planícies de restinga (em áreas mais abertas), e manguezais onde há maior facilidade da penetração da água salgada, sendo por isso, um lugar propício para a pesca dos Robalos. A característica climática predominante, segundo Köppen, é o clima tipo Tropical com temperatura média superior a $18{ }^{\circ} \mathrm{C}$, e precipitação anual em torno de 1.600 a 2.000 mm, sem estação seca (Rossi, 1999).

Figura 1: Canal de Bertioga e a localização do ponto visitado. Fonte: Google Maps.

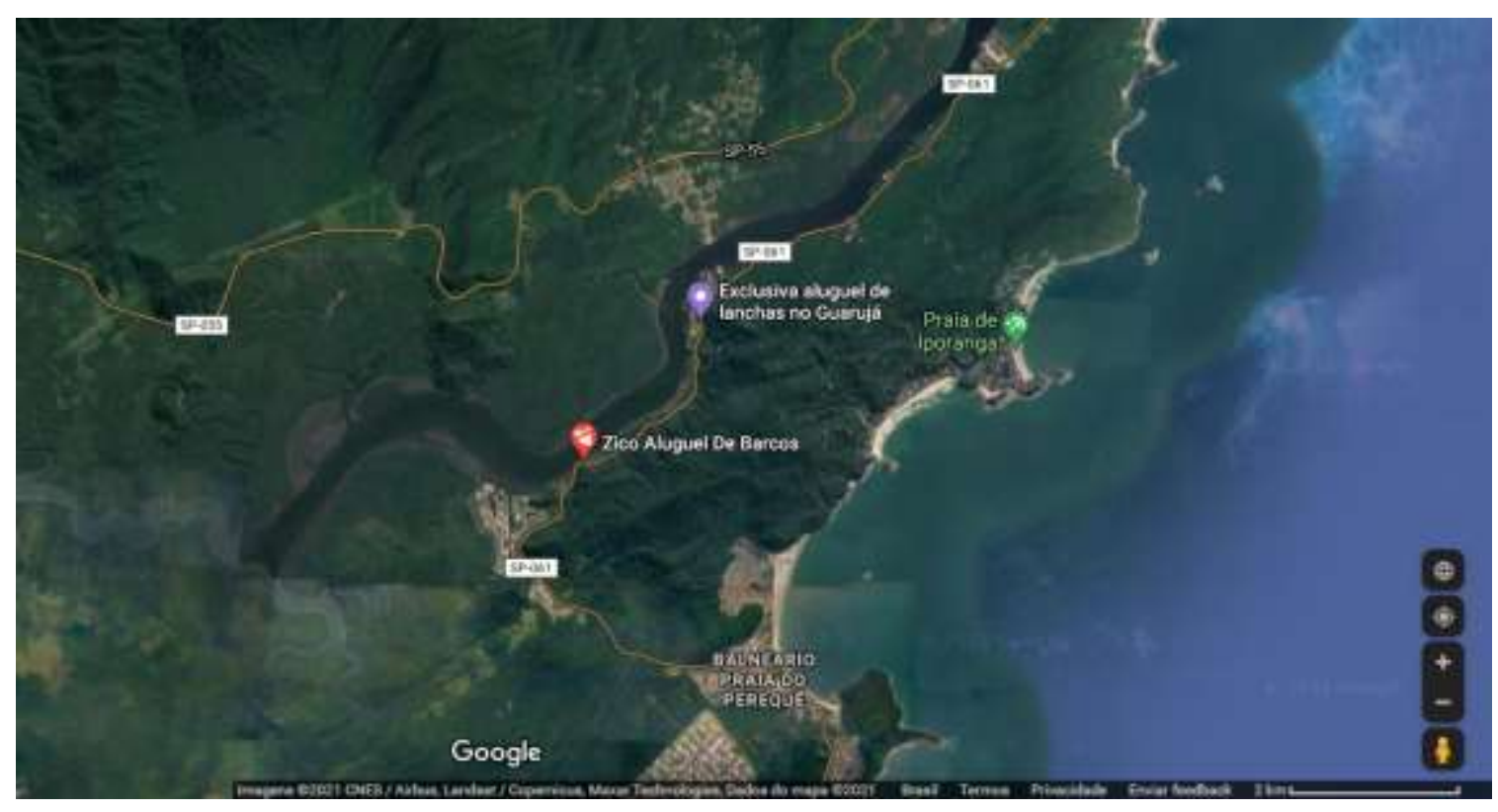

Fonte: Autores.

A pesquisa qualitativa ocorreu no Canal de Bertioga, nos mesmos moldes do trabalho de Ramires \& Barrella (2001), num estabelecimento privado de aluguel de embarcações de pequeno porte, localizado na margem esquerda do Canal de Bertioga, no Municipio de Guarujá. Além da observação direta da infraestrutura do local, outras informações sobre a caracterização socioambiental foram tomadas através de conversa com dois prestadores de serviços do estabelecimento e, que atuam também como pescadores artesanais. A rotina de pesca local, foi registrada, bem como, os principais problemas causados pelo uso frequente do canal, por donos de embarcações de pequeno e médio porte. Os dados foram analisados de forma descritiva, observando os relatos citados, buscando representar o consenso entre os informantes.

\section{Resultados}

O estabelecimento visitado é uma propriedade particular, sendo que o proprietário também atua na pesca artesanal e captura de iscas naturais que as comercializa aos pescadores amadores e outros pesqueiros próximos. O local apresentou a grama devidamente aparada, e todos os barcos presos, suspensos, fora da linha d'água. Sendo necessária a retirada manual da embarcação do pedestal de madeira para uma carreta de madeira que leva até a base da rampa de acesso para o canal. Esse processo de manuseio é feito pelo pescador amador que aluga o barco, tento em vista que o proprietário está sempre sozinho e não dispõe de meios tecnológicos para as subidas e descidas náuticas. 
Em relação a infraestrutura, a propriedade oferece um banheiro, com pia simples com água corrente e um vaso sanitário com uma descarga que reutiliza a água captada da pia, porém não possui vestiário. Estão disponíveis para aluguel, 12 embarcações, medindo até 6 metros de comprimento, feitas em alumínio, sem o acréscimo de motor, porém possuem dois remos de madeira e um guarda-sol, dentro do barco. As diárias dos barcos custam em torno de $\mathrm{R} \$ 150,00$ e podem ser utilizadas durante o dia todo (Figura 2). O cliente traz seu próprio motor de popa para acessar os pontos de pesca distantes. Caso contrário, é orientado aos pontos de pesca mais próximos a marina. Os pescadores amadores trazem seus próprios equipamentos de pesca e contam apenas com o aluguel de barcos e o fornecimento de iscas vivas. Dentro do estabelecimento há ainda pequena tábua, próxima a rampa de acesso para que o cliente possa descamar os peixes e descartar os restos de iscas vivas que não foram usadas durante a pescaria. Isso o auxilia no controle dos peixes pescados, bem como o descarte dos resíduos gerados na pescaria, como restos de alimentos, bebidas, linhas de pesca, utensílios quebrados ou que são inservíveis.

Figura 2: Embarcações de alumínio disponíveis para locação aos pescadores amadores em Bertioga/SP.

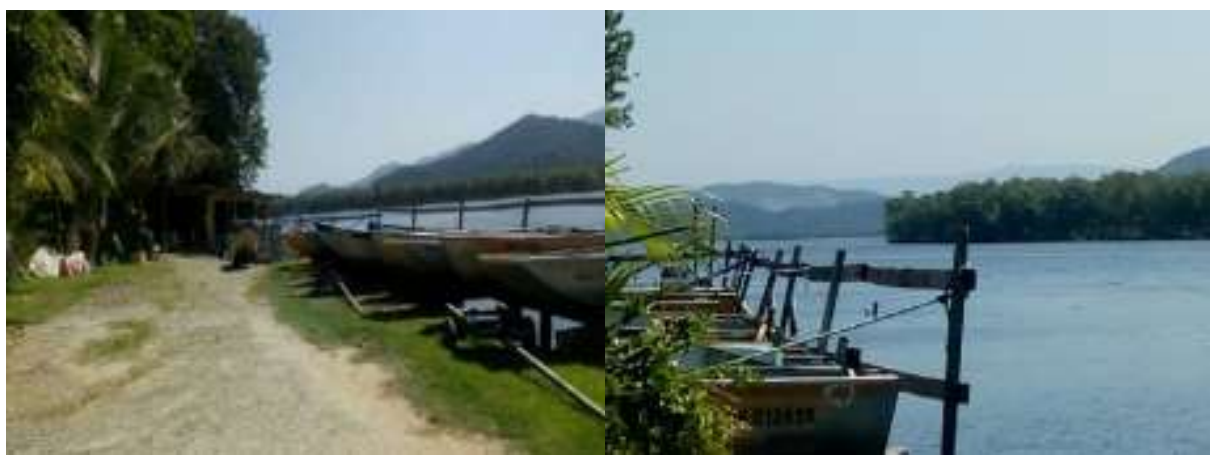

Fonte: Autores.

O proprietário oferece também orientações sobre as espécies de peixes disponíveis para pesca (fora do período de desova), além de dicas sobre possíveis locais e horário para a captura. Os clientes da marina visitada apoitam o barco na margem direita do canal, onde há raízes mais preservadas, sendo que os robalos procuram essas raízes e galhadas caídas para se alimentarem e se refugiarem. Eles relataram também que durante a "pesca ancorada" no período de Lua Minguante, oferece maiores oportunidades de pescaria. Porém se o sistema de pesca preferido é a "rodada", seguindo o fluxo de maré mais intenso que se dá na Lua Cheia e Nova.

A pesca esportiva que ocorre no Canal de Bertioga, gera renda para os pescadores artesanais através do aluguel de barcos, motores, serviços de guias para pesca e venda de iscas vivas. Com a pandemia de COVID-19, que iniciou em 2020, houve a necessidade de isolamento social e a restrição das atividades econômicas, que dificultou a realização de pescarias. A pesca dos robalos é ainda uma atividade importante para a pesca comercial (artesanal), uma vez que os peixes capturados são vendidos aos bares e restaurantes da região. Ambas as atividades, artesanal e amadora, movimentam financeiramente a região e, no período da pandemia do COVID-19, se tornou mais importante para a alimentação dos moradores locais que tiveram déficits em suas rendas, com a redução de frequentadores, causado pelas restrições impostas. Entre as alterações causadas no período de "lockdown", a mudança na frequência e número de pescadores amadores foi a principal. No auge da restrição das atividades consideradas não essenciais, o aluguel de barcos sofreu uma redução drástica e, os poucos alugados, foram em dias não habituais da atividade amadora, em dias úteis da semana. A coleta dos camarões, utilizados como isca, é uma atividade que também se manteve durante a pandemia, embora reduzida. É realizada através do "Jerivá", um equipamento artesanal, em forma de arco, que é passado na margem direita do Canal, do fundo do Rio para a superfície. Dessa forma, ele captura o camarão pequeno, e os 
mantém em tambores perfurados, parcialmente afundados e presos em estacas de madeira a uma distância visível da margem, onde saem os barcos para pescarias (Figura 3).

Figura 3: Armazenamento de iscas vivas.
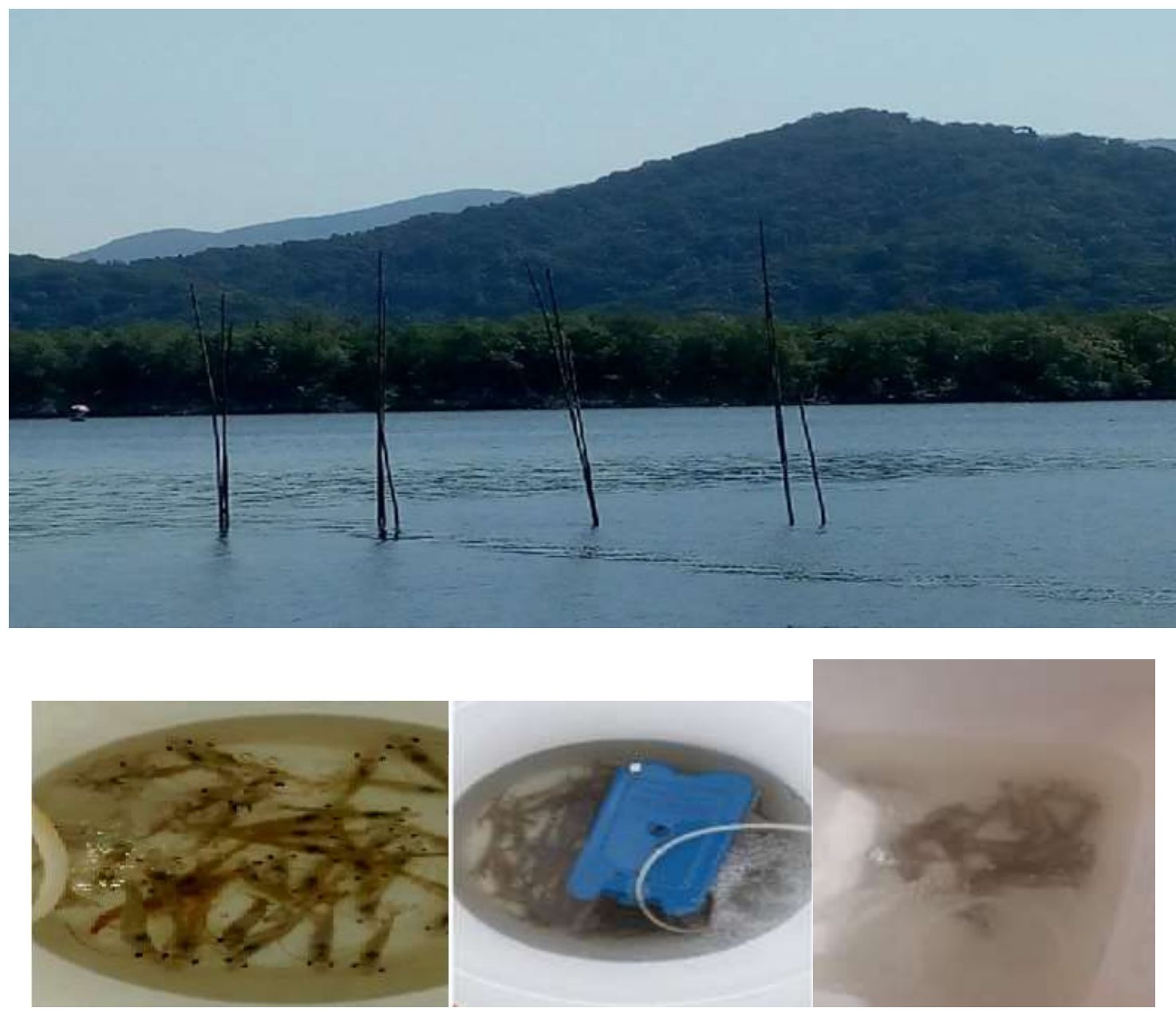

Fonte: Autores.

A média de permanência dos pescadores amadores no rio, tem sido de 6 horas e o período de maior movimentação, na marina, ocorre no começo da manhã, a partir das 6 horas, quando as embarcações começam a ser preparadas para as locações. Outro fato observado foi o aumento da frequência e movimentação das embarcações de maior porte, originárias principalmente, dos condomínios de alto padrão existentes ao longo do canal. Essas embarcações, por vezes, não respeitam os limites de velocidade de tráfego no canal, nem a quantidade de pessoas definida pelo plano de contingência à covid, do governo estadual (Plano SP de Contingência). Os movimentos intensos de embarcações no canal prejudica a estabilidade da vegetação, causando $\mathrm{o}$ assoreamento das margens e prejudicando o acesso de pequenas embarcações ao rio, além de alterar as caracteristicas naturais dos refúgios (galhadas) com a redução de peixes e botos, reduzindo a biodiversidade local. Os pescadores relataram o aumento dessas deformidades ao longo dos últimos anos, causada pelo excesso do limite de velocidade permitido das embarcações (5 nós) afetando diretamente toda a estabilidade de ancoragem das árvores do manguezal, principalmente durante os feriados, férias escolares e finais de semana com tempo bom. 


\section{Discussão}

Embora, com frequência reduzida, observamos que a pesca amadora passou a ser um lazer individual alternativo, podendo ser praticada sem aglomerações, por muitos pescadores, semelhantes àqueles de parques e áreas urbana abertas (Corbari \& Grimm, 2020). Neste sentido, o estabelecimento com infraestrutura mais simples, fomentou a prática da atividade sem aglomerações, diferente dos estabelecimentos que contam com meios de hospedagem e restaurantes, que tiveram redução mais drástica em seus rendimentos. Assim, as marinas a beira do rio, que atenderam os protocolos sanitários estabelecidos e respeitando as normas de restrição de atividades impostas pelo Plano de Contingência de São Paulo (São Paulo, 2021), atuaram minimamente, para garantir sua manutenção e garantir alimentação das famílias. Mesmo com a intensificação da fiscalização devido ao aumento de movimentação de embarcações de pequeno e médio porte trafegando no Canal, ainda assim a atividade pesqueira se manteve. $\mathrm{O}$ ambiente foi visitado com maior frequência por pescadores esportivos, devido ao fato de ter disponível a embarcação para o aluguel, a facilidade de locação devido as restrições de circulação, pois a procura diminuiu, e a atividade poder ser desempenhada de forma isolada, não comprometendo assim a segurança sanitária dos praticantes. A atividade pesqueira esportiva, representou fator de somatória aos ganhos financeiros dos pescadores artesanais que forneceram insumos necessários para a continuidade da atividade. Dessa forma, em meio ao fechamento de bares e estabelecimentos comerciais, o fornecimento de iscas e aluguel de barcos, tornou-se uma importante fonte de renda alternativa, além do fornecimento do pescado para o comércio alimentício próximo.

O Canal de Bertioga é intensamente trafegado por embarcações de diferentes tamanhos, sendo por isso necessários que estes respeitem a legislação vigente (Cunha, 2006). O ambiente do manguezal vem sofrendo impactos decorrentes da movimentação da água, desestabilizando as margens e a vegetação nativa (Moreira Junior, 2010; Martins, et al 2008). Dessa forma foi possível observar, através das raízes das árvores e seus troncos adernados, que essa constante movimentação é um fator de degradação recorrente no ambiente, prejudicando a estabilidade das margens. O aumento na fiscalização inibiria a velocidade excessiva contribuindo para a recuperação dos habitats dos peixes e consequentemente dos estoques pesqueiros (Buchianer, 2017; Souza et al., 2018). A atividade pesqueira, seja ela artesanal ou esportiva, depende diretamente que o ambiente esteja saudável e com bons índices de procriação das espécies marinhas (Claudio et al., 2019). O robalo é um peixe que pode atingir tamanhos superiores em relação a outras espécies presentes no canal (Barroso et al., 2002 e 2007), e por isso, atrai mais pescadores sua captura.

A atividade de pesca amadora fornece, ao longo do ano, a oportunidade financeira adequada para a complementação da renda dos pescadores artesanais, pois eles oferecem e fornecem insumos, recolhidos através da prática e conhecimento da atividade no ambiente do Canal de Bertioga (da Silva et al., 2019; Rodrigues et al., 2020; Rotundo et al., 2020). Essas duas atividades, tornam-se financeiramente interdependentes, pois ambas dependem dos conhecimentos compartilhados e dos pagamentos efetuados para o êxito na captura do robalo, fonte atrativa dos pescadores esportistas que procuram o canal. O isolamento social provocado pela COVID-19, está sendo visto como uma oportunidade de aumentar a frequência de turistas de pesca, como ocorreu ao longo do litoral de São Paulo e Rio de Janeiro (Carneiro \& Allis, 2021). Por outro lado, as medidas restritivas como fechamento do comércio e barreiras sanitárias prejudicaram a pesca esportiva com perda monetária para pescadores artesanais locais.

\section{Conclusão}

A relação estabelecida entre a pesca artesanal e recreativa que ocorre no Canal de Bertioga apresenta interdependência, uma vez que, complementam a renda e a movimentação econômica nas comunidades de pescadores residentes nesse ambiente costeiro.

O descontrole da velocidade de tráfego no canal atrapalha a prática da pesca, além de prejudicar a vegetação e a fauna. 
Os pescadores artesanais orientam os pescadores esportivos, sobre os períodos de desova dos peixes e também o descarte irregular de resíduos produzidos durante as pescarias.

A pesca amadora no Canal de Bertioga é pouco estudada, com diversas lacunas do conhecimento.

\section{Referências}

Ager, L.A., Hammond, D. E., \& Ware, F. (1976). Artificial spawning of snook, Centropomus undecimalis. In: Annual Conference Of The Southeastern Association Of Fish And Wild Life Commmissioners, 10, Hamburg. Proceedings... 158-166.

Barbanti, B., Caires, R. \& Marceniuk, A. P. (2013). A ictiofauna do canal de Bertioga, São Paulo, Brasil. Biota Neotropica, 13(1), 276-291

Barroso, M. V., Souza, G. A. P., Thomé, J. C. A., Leite Júnior, N. O. P., Moreira, L. M. P., Sangalia, C., Sales, E. F. \& Durão, J. N. (2007) Estratégias de conservação das populações de robalo-flexas Centropomus spp. na foz do Rio Doce, Linhares, Espírito Santo, Brasil. Revista Brasileira de Agroecologia, 2(2): 1465-1468.

Barroso, M. V., Castro, J. C., Aoki, P. C. M. \& Helmer, J. L. (2002). Valor nutritivo de alguns ingredientes para o robalo (Centropomus parallelus).

Revista Brasileira de Zootecnia, 31(6): 2157-2164.

Buchianeri, V. C. (2017). O valor dos serviços ecossistêmicos nas bacias hidrográficas dos rios Itaguaré e Guaratuba em Bertioga, SP. (Doctoral dissertation, Universidade de São Paulo).

Corbari, S. D. \& Grimm, I. J. (2020). A pandemia de covid-19 e os impactos no setor do turismo em Curitiba (PR): uma análise preliminar. Ateliê do Turismo, 4(2), 1-26.

Carneiro, J. \& Allis, T. (2021). Como se move o turismo durante a pandemia da COVID-19? Revista Brasileira de Pesquisa em Turismo, 15(1).

CIMA (1991). Subsídios técnicos para elaboração do relatório nacional do Brasil para a Conferência das Nações Unidas sobre Meio Ambiente e Desenvolvimento. Brasília, Comissão Interministerial para a preparação da preparação a Conferência das Nações Unidas sobre Meio Ambiente e Desenvolvimento, $172 \mathrm{p}$.

Chávez, H. (1963). Contribución ao conocimiento de la biologia de los robalo-flexa schucumite y constantino (Centropomus spp) del estado de Vera Cruz (Pisc. Centrop.), México. Ciência, 2(5): 141-161.

Claudio, L., Murua, G., Kefalas, H. C., Barbosa, A. C. S., de Oliveira, A. F. S., Fialho, A., \& de Oliveira, M. R. (2019). Semeando O Saber, Adquirindo O Poder. Mares: Revista de Geografia e Etnociências, 1(1), 161-174.

Cunha, I. A. D. (2006). Fronteiras da gestão: os conflitos ambientais das atividades portuárias. Revista de Administração Pública, 40(6), 1019-1040.

Gurgel, A. D. M., Santos, C. C. S. D., Alves, K. P. D. S., Araujo, J. M. D., \& Leal, V. S. (2020). Estratégias governamentais para a garantia do direito humano à alimentação adequada e saudável no enfrentamento à pandemia de Covid-19 no Brasil. Ciência \& Saúde Coletiva, 25, $4945-4956$.

IBGE Instituto Brasileiro de Geografia Física. (2004). Mapa de Biomas do Brasil, Mapa Climático Brasileiro, primeira aproximação. IBGE

Martins, S. E., Rossi, L., Sampaio, P. D. S. P., \& Magenta, M. A. G. (2008). Caracterização florística de comunidades vegetais de restinga em Bertioga, SP, Brasil. Acta Botanica Brasilica, 22(1), 249-274.

Moreira Junior, W. (2010). Adaptações dos pescadores artesanais aos impactos ambientais sobre os manguezais do estuário da Baixada Santista. Periódico Eletrônico Fórum Ambiental da Alta Paulista, 6(11).

São Paulo, Estado. (2021). Plano São Paulo de Contingência ao Avanço da Pandemia de Sars Covid 19. https://www.saopaulo.sp.gov.br/wpcontent/uploads/2021/03/24-balanco-plano-sp-20210303-1.pdf

Pereira, M. E. G. de S., Silva, B. B., Rocha, R. M., Asp-Neto, N. E., Silva, C. S. \& Nunes, Z. M. P. (2015). Bioecologia Do Robalo-Flexa, Centropomus undecimalis, Em Lagoa Costeira Tropical No Norte Do Brasil. Bol. Inst. Pesca, São Paulo, 41(3): 457 - 469.

Pereira, M. E. G. de S., Cañete, V. R., Palheta, M. K. S., Santos, F. J. S., Silva, B. B., Barboza, R. S. L., \& Evangelista-Gomes, G. (2020). Contribuição dos atores da pesca para a bioecologia do Camurim Centropomus undecimalis (Centropomidae - Perciformes) capturado no litoral Amazônico brasileiro. Research, Society and Development, 9(10), e4119108691. https://doi.org/10.33448/rsd-v9i10.8691

Ramires, M. \& Barrella, W. (2001). A Pesca Esportiva como Alternativa Econômica numa Comunidade Caiçara da Estação Ecológica de Juréia Itatins-SP. Revista Ciências Biológicas e do Ambiente PUC-SP. 3(1), 39-51.

Ramires, M. \& Molina, S. M. G. (2004). Influências da Pesca Esportiva no Modo de Vida dos Pescadores Caiçaras do Vale do Ribeira. In: IV Encontro LatinoAmericano de Pós-graduação, 2004, São José dos Campos. Anais de Resumos IV Encontro Latino-americano de Pós-graduação, 2004. <http://www.inicepg.univap.br/cd/INIC_2004/trabalhos/epg/pdf/EPG2-1.pdf>

Rodrigues, R. P., Pereira Junior, J. de A., Brabo, M. F., Santos, F. J. da S., Aranha, T. V., \& Santos, M. A. S. dos. (2020). A pesca esportiva marinha no Município de São Caetano de Odivelas, Estado do Pará, Amazônia, Brasil. Research, Society and Development, 9(7), e835974701. https://doi.org/10.33448/rsd-v9i7.4701

Rossi, M. Fatores formadores da paisagem litorânea: A Bacia do Guaratuba, São Paulo-Brasil. São Paulo. Universidade de São Paulo, 1999. 168p. (Tese de Doutorado). 
Research, Society and Development, v. 10, n. 6, e27010615805, 2021

(CC BY 4.0) | ISSN 2525-3409 | DOI: http://dx.doi.org/10.33448/rsd-v10i6.15805

Rotundo, M. M., Gaulia, L. A., Cardoso, G. S., Carminatto, A. A., Henrique, H. S., Reigada, Álvaro L. D., Ramires, M., Barrella, W. \& Petrere Junior, M. (2020). Ictiofauna do alto estuário de Santos-São Vicente: um estudo antes e durante o incêndio no terminal portuário de Santos. Research, Society and Development, 9(10), e6269108901. https://doi.org/10.33448/rsd-v9i10.8901

Silva, L. D. M. C., Machado, I. C., dos Santos T., S. L. \& Tomás, A. R. G. (2019). Calendário etnobiológico do robalo, segundo os pescadores especialistas das áreas estuarinas da Baixada Santista (SP). CIAIQ2019, 3, 457-466.

Da Silveira Menezes, A. A., Lin, C. F., Silva, C. \& dos Santos, R. A. (2012). Aspectos socioeconômicos relacionados à pesca amadora de robalo (Centropomus undecimalis e C. parallelus) na Baía da Babitonga, Santa Catarina, Brasil. Revista CEPSUL-Biodiversidade e Conservação Marinha, 3(1), 22-44.

Souza, C. A., Duarte, L. F. A., João, M. C. \& Pinheiro, M. A. (2018). Biodiversidade e conservação dos manguezais: importância bioecológica e econômica. Educação Ambiental sobre Manguezais. Unesp, 16-56. 